\title{
Modification, Homogenization, Intensification of Heat Transfer as the Main Levers Controlling the Properties of Cast Semi Finished Products
}

\author{
Andrey A. Guschinskiy*a, \\ Evgeniy A. Pavlov ${ }^{\mathrm{a}}$, Edward V. Maltsev', \\ Alexander P. Skuratov ${ }^{b}$ and Sergey V. Belyaev ${ }^{b}$ \\ "JSC "Krastsvetmet" \\ 1 Transportny, Krasnoyarsk, 660027, Russia \\ ${ }^{b}$ Siberian Federal University \\ 79 Svobodny, Krasnoyarsk, 660041, Russia
}

Received 26.01.2015, received in revised form 12.02.2015, accepted 19.04.2015

The article discusses the main ways of controlling the properties of gold jewelry alloys. We analyzed the types of modifiers and the role of alloying components in alloys. There are described study the effect of the crystallization rate on patterning modifying alloys and their role in the inheritance of a homogeneous, fine-grained structure of the base, target alloy. Here are described analytical and technological-mechanical equipment, which is used in the development of new alloys and modes of their production.

Keywords: modifier, granulation, ligature alloy, gold jewelry alloy.

(C) Siberian Federal University. All rights reserved

* Corresponding author E-mail address: aguschinskiy@mail.ru 


\title{
Модифицирование, гомогенизация, \\ интенсификация теплопереноса \\ как основные рычаги управления \\ свойствами литого полуфабриката
}

\author{
А.А. Гущинский ${ }^{a}$, Е.А. Павлов ${ }^{a}$, \\ Э.В. Мальцев ${ }^{a}$, А.П. Скуратов ${ }^{\sigma}$, С.В. Беляев ${ }^{\sigma}$ \\ ${ }^{\text {a } О А O ~ « К р а с и я в е т м е т » ~}$ \\ Россия, 660027, Красноярск, Транспортный проезд, 1 \\ ${ }^{6}$ Сибирский федеральный университет \\ Россия, 660041, Красноярск, Свободный, 79
}

В статье рассматриваются основные пути управления свойствами золотых ювелирных сплавов. Анализируются типь модификаторов, роль легирующчих компонентов сплавов. Описано исследование влияния скорости кристаллизациина структурированиесплавовлигатур и их роль в наследовании гомогенной, мелкозернистой структуры основныл, целевым сплавом. Описано аналитическое и технологическое оборудование, используемое при разработке новых сплавов, а также режимы их получения.

Ключевые слова: модификатор, гранулирование, сплав, лигатура, золотой ювелирный сплав.

Свойства сплава во многом определяются исходной литой структурой, которая зависит от его состава и условий кристаллизации. При плавлении многокомпонентных систем и последующем их затвердевании недостаточные скорости охлаждения приводят к развитию ликвационных процессов, в сплаве могут возникать микрогетерогенность химического состава и пористость, приводящие к возникновению неоднородности его физико-механических характеристик плотности, твердости, что в дальнейшем отражается на нестабильности стадий пластической деформации.

Одной из основных характеристик, позволяющих оценить свойства сплавов, является размер зерен в его микроструктуре. Уменьшение размера зерен вызывает увеличение протяженности границ, что сопровождается повышением прочности, сохраняет высокую пластичность, повышает однородность химического состава. На размер зерен оказывают влияние скорость кристаллизации и модифицирующие добавки [1].

Модификаторы по механизму поведения в расплаве и кристаллизации подразделяют на три группы [2]:

1. Модификаторы, повышающие смачиваемость одной составляющей сплава другой, т.е. снижающие поверхностное натяжение на границе между ними, и тем самым снижающие работу образования единицы поверхности твердой фазы - центра кристаллизации.

2. Модификаторы, являющиеся непосредственными зародышами кристаллизации.

3. Инокуляторы-модификаторы, изменяющие литую структуру за счет уменьшения перегрева кристаллизующегося металлического расплава. 
В качестве примера для подтверждения вышеизложенных тезисов предлагается обзор исследования технологии получения литого полуфабриката из ювелирного золотого сплава 585 -й пробы.

Величина объема продаж на ювелирном рынке России постоянно изменяется. Во многом спрос на ювелирные изделия зависит от уровня жизни населения. Наиболее популярными и востребованными у россиян являются изделия из золота 585-й пробы [3].

Если рассматривать рынок продаж ювелирных изделий по позициям, то $70 \div 75$ \% приходится на цепочки, браслеты и ожерелья из драгоценных металлов без камней [1]. Ввиду высокой массовости наиболее востребованных изделий их производство ориентированно на машинные технологии. Это означает, что доля участия человека в производстве изделий минимальна.

Стабилизация физико-механических характеристик ювелирного сплава для дальнейшей его обработки - актуальная задача при производстве ювелирных изделий на предприятиях, работающих с применением машинных технологий.

Основными легирующими компонентами ювелирных золотых сплавов являются медь и серебро. Широкое применение этих элементов в качестве легирующих обусловлено тем, что они имеют большую растворимость в золоте и обеспечивают его необходимыми технологическими и эстетическими свойствами.

Медь повышает твердость золотого сплава, сохраняя ковкость и тягучесть, за счет образования интерметаллических соединений в твердом состоянии. При повышении содержания меди золотой сплав постепенно приобретает красноватые оттенки, и при её содержании 14,6 масс. \% и более сплав становится ярко-красным.

Серебро придает золотому сплаву мягкость и ковкость, понижает температуру плавления, изменяет цвет. С увеличением содержания серебра цвет сплавов изменяется от желтого

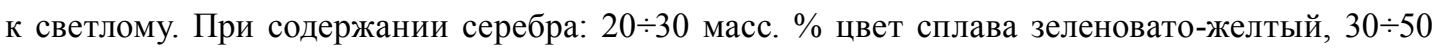

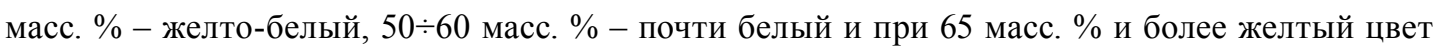
сплава полностью исчезает. Сплавы золото-серебро хорошо поддаются механической обработке и представляют собой непрерывный ряд твердых растворов.

Бинарные сплавы золота не получили своего практического применения из-за невозможности придания им всего комплекса необходимых свойств, поэтому для производства ювелирных изделий используются многокомпонентные сплавы, в частности тройная система $\mathrm{Au}-\mathrm{Ag}-\mathrm{Cu}$ [4].

Для повышения жидкотекучести к золотым сплавам добавляют цинк. Благодаря добавкам цинка сплавы приобретают желтоватый цвет. Небольшие добавки цинка значительно сужают область плавления тройного сплава $\mathrm{Au}-\mathrm{Ag}-\mathrm{Cu}$.

Химические составы применяемых ювелирных золотых сплавов известны и включены в ГОСТ 30649-99. Однако работы по улучшению свойств за счет легирования, микролегирования и модифицирования продолжаются.

В работе [4] рассматривается способ ввода в золотой сплав в качестве модификатора иридия и его воздействие на структуру. Единственным его недостатком является высокая стоимость.

Также в различных источниках [5] описывается модифицирующее влияние рутения, недостатком применения которого выступает трудность ввода требуемого количества в состав сплава.

В [6] выполнена разработка нового состава ювелирного золотого сплава, в котором обоснована добавка хрома, позволяющая добиться модифицирующего воздействия на микро-

$$
-533-
$$


структуру при кристаллизации. Ввод хрома в состав золотого сплава осуществляется через медь. Ограниченная растворимость золота и меди в хроме приближает выделяющуюся из расплава твердую фазу по свойствам к хрому, температура кристаллизации которого значительно выше, чем у всех остальных компонентов, входящих в состав золотого ювелирного сплава. Первоочередная кристаллизация фазы на основе хрома обеспечивает зарождение центров кристаллизации в объеме расплава без его переохлаждения. Таким образом, хром выступает в роли инокулятора.

Для достижения гомогенности в многокомпонентном сплаве разработаны различные методы воздействия на металл как при его плавлении, так и при кристаллизации. В [7] описано положительное влияние увеличения скорости кристаллизации на формирование структуры отливки. Высокая скорость кристаллизации расплавов (более $100{ }^{\circ} \mathrm{C} / \mathrm{c}$ ) позволяет исключить целый ряд металлургических дефектов и несовершенств и получить сплав со значительно улучшенным комплексом свойств.

Повышение скорости охлаждения при кристаллизации приводит к существенным структурным изменениям и получению металлов с улучшенными свойствами:

- измельчением ветвей дендритов, образующихся из-за несоответствия скоростей теплоотвода и массопереноса;

- уменьшению химической неоднородности;

- образованию субдендритной структуры литого металла[8].

Наиболее простым и широко применяемым в промышленности способом повышения скорости охлаждения является гранулирование металлического расплава.

Стандартная технология производства гранул включает получение однородного металлического расплава в плавильной литейной установке с индукционным нагревом в инертной атмосфере и его гранулирование с кристаллизацией в емкость с водным раствором. Полученные гранулы сушат и классифицируют по крупности. После анализа макро- и микроструктуры полученных гранул делают заключение о выходе класса гранул оптимального размера, обладающих всеми характеристиками качественных лигатур. Оценка производится по следующим критериям:

- химическая однородность;

- однородность по цвету и размеру;

- правильность формы;

- отсутствие на поверхности гранул трещин и литейных дефектов;

- отсутствие пор в объеме гранулы.

При получении гранул процесс теплообмена тесно связан с величиной теплоемкости расплава и энтальпии перехода в твердое состояние. Эти физические параметры определяют продолжительность превращения жидкой капли в твердую частицу.

$$
t=\frac{\rho_{m}}{6 \beta}\left[C_{p} \ln \left(\frac{T_{M}-T_{0}}{T_{S}-T_{0}}\right)+\frac{\Delta H_{S}}{T_{S}-T_{0}}\right],
$$

где $T_{o}$ - температура среды, окружающей каплю расплава; $T_{M}$ - температура плавления; $T_{S}-$ температура кристаллизации; $\Delta H_{S}$ - теплота плавления; $C_{p}$ и $\rho_{m}-$ теплоемкость и плотность расплава; $\beta$ - коэффициент конвективной теплопередачи. 
При получении порошков способом распыления расплавов микрообъемы жидкого металла, образующиеся в результате разрушения струи расплава, имеют неправильную форму. Благодаря существенному перегреву расплава над температурой ликвидуса происходит сфероидизация этих микрообъемов под действием сил поверхностного натяжения. Если частица затвердевает до завершения сфероидизации, ее форма не является сферической.

$$
t_{S}=\frac{12 \pi^{2} \eta}{\gamma V}\left(D^{4}-d^{4}\right),
$$

где $\eta$ - кинематическая вязкость расплава; $\gamma$ - поверхностная энергия расплава; $D$ - диаметр капли; $d$ - диаметр струи; $V$ - объем струи.

Сокращение продолжительности сфероидизации обеспечивается низкой вязкостью расплава (высоким уровнем перегрева над температурой ликвидуса). Высокое значение поверхностной энергии и малые размеры капель обеспечивают их сфероидизацию до начала затвердевания, поэтому мелкие частицы порошков, полученных распылением расплавов, более близки по форме к сферическим, чем крупные [9].

Процесс распыления металлических расплавов в состоянии, отвечающем минимально достижимым значением поверхностного натяжения и кинематической вязкости, является оптимальным. В этом случае дисперсность получаемого порошка зависит только от скорости газового потока.

В процессе распада струи и формирования строения и геометрии частиц важную роль наряду со значениями поверхностной энергии расплавов играет переохлаждение расплавов, которое в малых объемах металла может достигать нескольких сотен градусов.

Широкое применение процессов распыления жидкостей объясняется тем, что с уменьшением размеров капель резко улучшаются условия тепло- и массообмена, ускоряется протекание технологических процессов, снижаются габариты соответствующей аппаратуры.

В $[10,11]$ были проведены исследования влияния на структуру гранул лигатуры температуры расплава и водного раствора. Состав лигатуры следующий: $\mathrm{Cu}-84,7, \mathrm{Ag}-12,1, \mathrm{Zn}-3,1$, $\mathrm{Cr}-0,07$ масс. \%.

Хром для удобства вводился в виде прутков хромистой бронзы БРХ1 ГОСТ 18175-78.

Исследования проведены на индукционной литейной установке Neutec 515 (США) с уникальной технологией пульсирующего силового перемешивания для повышения гомогенности расплава. В камеру печи подается инертный газ, создающий некоторое избыточное давление над зеркалом расплава. Слив осуществляется через отверстие в донной части тигля, которая закрывается графитовым штоком. Температуру в центре расплава контролирует термопара, вмонтированная в запорный шток тигля.

Слив расплава производится в бак-гранулятор, наполненный водным раствором с добавкой некоторого количества спирта. Пространство между донной частью тигля и поверхностью водного раствора защищено специальной камерой, в которую подается инертный газ. Для управления температурой и поддержания ее в баке-грануляторе используется змеевик из медной трубы, который при помощи гибких шлангов подключается к термостату типа KRIOVT-01. Температуру водного раствора контролировали с помощью контактного термометра, вмонтированного в торцевую часть бака-гранулятора. Полученные гранулы сушатся в токе 
горячего воздуха на универсальном сушильном аппарате TG 100. По окончании каждого опыта проводили ситовой анализ для выявления фракции с наибольшим выходом на анализаторной просеивающей машине Retsch AS 200. Контроль микроструктуры гранул осуществляли при помощи комплекса оборудования для металлографического контроля, включающего 5-тонный пресс «Metapress» для запрессовки исследуемых образцов в полимер, двухдисковый шлифовальный станок с устройством для крепления и перемещения образцов Gripo 2V, микроскоп «Axiovert» 40 MАТ для светлого и темного поля отраженного света фирмы Carl Zeiss и модульную программную систему обработки и анализа изображений «AxioVision».

Предварительно экспериментально была установлена температура плавления исходной шихты. В процессе исследований варьировалась температура перегрева расплава перед его сливом. Максимальная величина температуры перегрева ограничивалась наличием в составе расплава легколетучих компонентов, в частности цинка.

Металлографический контроль полученных в результате опытов гранул лигатуры показал, что наиболее предпочтительный размер фракций находится в диапазоне от -4 до +2 мм (рис. 1 и 2). В этом диапазоне гранулы по внешнему виду и микроструктуре соответствовали заявленным критериям качества. Последнее позволяет утверждать, что полученные литейные свойства золотых ювелирных сплавов удовлетворяют требованиям технологии.

Дальнейший анализ показал, что грануляцию лигатуры следует проводить при температуре $1100{ }^{\circ} \mathrm{C}$. При этой температуре, независимо от температуры охлаждающей среды, были получены максимальные выходы фракции $-4 . .+2$ мм от всего объема расплава. Зависимость выхода фракции $-4 . .+2$ мм от температуры расплава при сливе показана на рис. 3.

В ходе экспериментальных исследований проведена также оценка влияния температуры охлаждающей среды на формирование гранул. Установлен температурный диапазон изменения охлаждающей среды, в котором происходит сфероидизация расплава (рис. 4).

Из приведенного графика видно, что температура, при которой происходит наибольший выход фракции $-4 \ldots+2$ мм, находится в диапазоне $10 \div 20^{\circ} \mathrm{C}$.

Для управления температурой и поддержания ее в баке-грануляторе используется змеевик из медной трубы, который при помощи гибких шлангов подключается к термостату типа KRIO-VT-01.

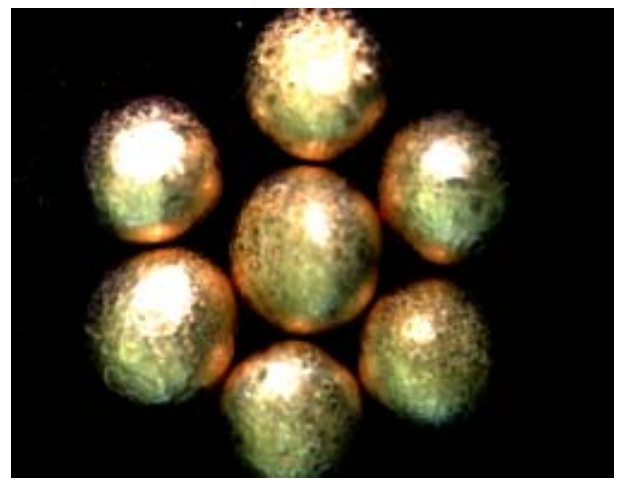

Рис. 1. Внешний вид гранул фракции $-4 . . .+2$ мм

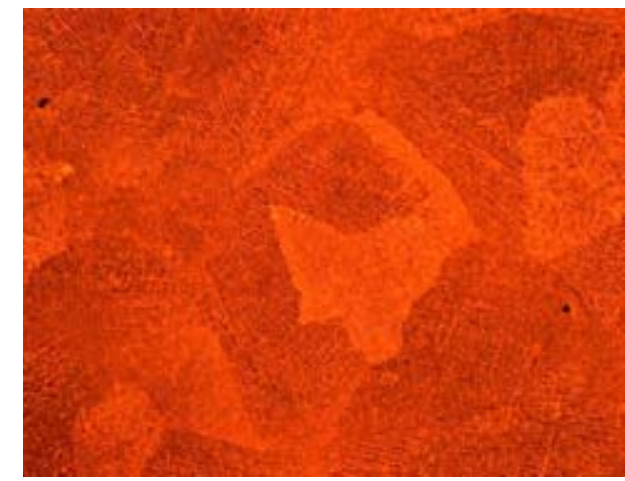

Рис. 2. Микроструктура гранул фракции $-4 . .+2$ мм $\mathrm{x} 100$ 


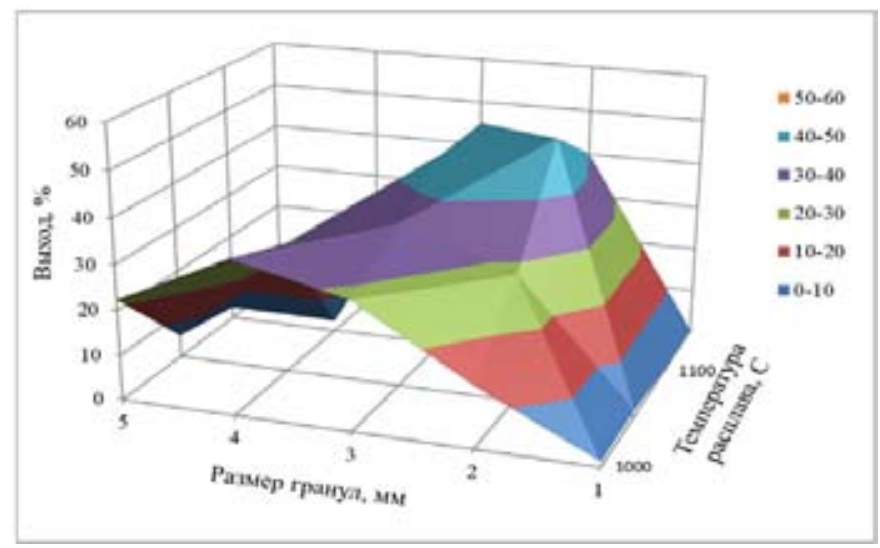

Рис. 3. Зависимость выхода (масс. \%) фракции $-4 . .+2$ мм от температуры расплава при сливе

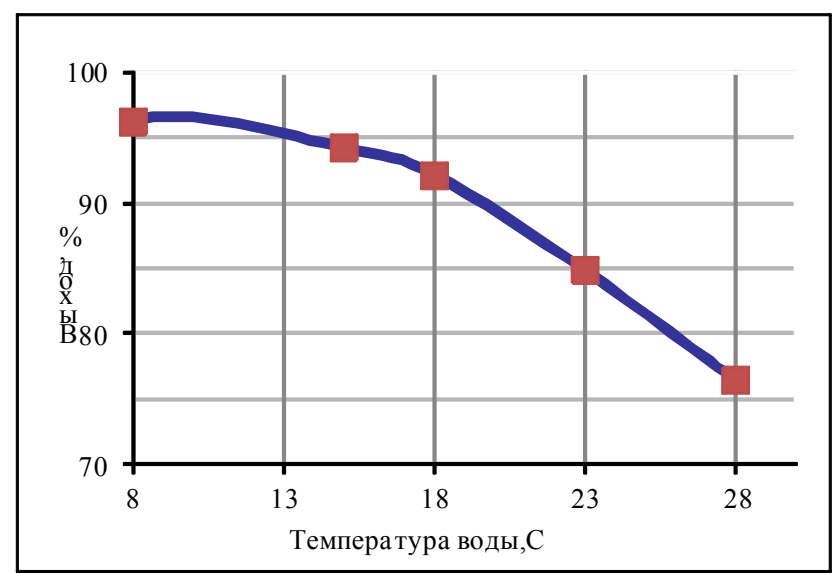

Рис. 4. Зависимость выхода ( \%) фракции -4...+2 мм от температуры воды при температуре расплава $1100{ }^{\circ} \mathrm{C}$

В дальнейшем гранулы лигатуры переданы на ювелирное производство ОАО «КРАСЦВЕТМЕТ» для получения золотого сплава 585-й пробы. Для этого их добавляли в расплав золота, выдерживали образующийся расплав небольшое количество времени перед сливом. Для получения цепей и браслетов из ювелирного золотого сплава требуется проволока различного диаметра. Поэтому плавка осуществляется на индукционной печи непрерывного типа IECO. Используемый способ имеет ряд преимуществ при получении полуфабрикатов для дальнейшей пластической деформации:

- полуфабрикаты обладают равномерным химическим составом и мелкой зеренной структурой;

- микроструктура длинных заготовок равномернее, что предотвращает возможные большие напряжения в заготовках;

- непрерывное литье снижает количество остатков и потерь металла по сравнению с литьем в форму; 
- конечным продуктом плавки является пруток круглого сечения.

В работе [12] описан технологический процесс получения сплава золота с использованием готовой лигатуры. Из литературы известно, что при литье низкая температура нагрева расплава обусловливает снижение жидкотекучести и повышение вязкости. Происходит «запутывание» в кристаллизующемся образце захваченных газовых пузырьков и включений, создаются благоприятные условия для образования неслитин, расслоений. В связи с этим на практике выбирают температуру на 100-200 들 превышающую температуру плавления. При этом слишком большой перегрев снижает скорость кристаллизации и приводит к увеличению летучести компонентов сплава. Экспериментально определена температура плавления золотого сплава $980{ }^{\circ} \mathrm{C}$. Температура расплава перед сливом должна находиться в диапазоне $1080-1180{ }^{\circ} \mathrm{C}$.

Исследуемый сплав отличается от стандартного присутствием в нем модифицирующей тугоплавкой добавки - хрома (Тпл $\left.=1890^{\circ} \mathrm{C}\right)$, который влияет на температуру плавления сплава.

Поэтому при плавлении исследуемого сплава температуру его перед сливом необходимо увеличить выше $1100{ }^{\circ} \mathrm{C}$, до 1160-1180 ㄷ. Гранулы сплава-лигатуры загружались непосредственно в тигель литейной машины, после нагрева до 1180 С была произведена (без изотермической выдержки) вытяжка расплава, со скоростью 10-11 см/мин в пруток. При этих условиях произошло формирование мелких зерен, соответствующих гомогенному распределению компонентов. Распределение хрома по всей длине равномерно и составляет 0,02%.

При кристаллизации происходит формирование однородных зёрен, что свидетельствует об эффективном массопереносе и теплоотводе и указывает на хорошее распределение модификатора по объёму полуфабриката. Такая структура благоприятна для дальнейшей деформации. Микроструктура финишной проволоки имеет мелкозернистое строение.

Изготовленная из экспериментального сплава проволока была направлена на передел цепевязания ювелирного производства. В зависимости от типа вязки цепей показатели выхода цепочек, изготовленных из экспериментального сплава, на переделе финишной обработки оказались выше на 4-29 \%, чем средний выход цепей по производству.

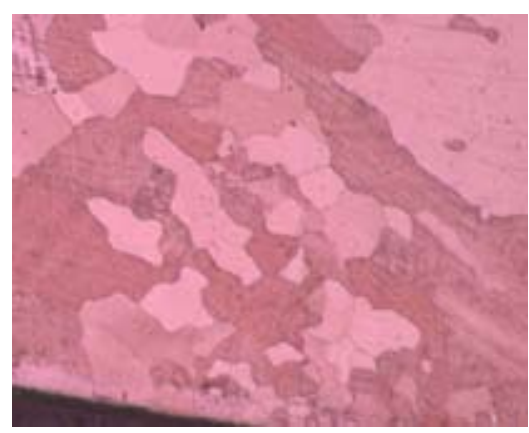

Рис. 5. Микроструктура литого прутка Ø8 мм из золотого сплава (1350 МПа), х100 


\section{Список литературы}

[1] Режим доступа: http://www.metaltorg.ru.

[2] Бреполь Э. Теория и практика ювелирного дела. СПб.: Соло, 2000. 528 с.

[3] Бокштейн С.3. Строение и свойства металлических сплавов. М.: Металлургия, 1971. $494 \mathrm{c}$.

[4] Павлов Е.А. и др. // Цветные металлы. 2008. № 3 С. 43-45.

[5] Карманный справочник по благородным металлам. Франкфурт: Дегусса АГ, 1995.

[6] Павлов E.A. и др. // Цветные металлы-2009: Сб. докладов I Международного конгресса. Красноярск, 2009. С. 625.

[7] Гущиинский А.А. и др. // Цветные металлы. 2010. № 11. С. 46-50.

[8] Ничипоренко О.С. и др. Распыленные металлические порошки. Киев: Наукова думка, $1980,240 \mathrm{c}$.

[9] Герман Р. Порошковая металлургия от А до Я. М.: Интеллект, 2009. 336 с.

[10] Гущинский А.А. и др. // Цветные металлы-2009: Сб. докладов I Международного конгресса. Красноярск, 2009. С. 347-351.

[11] Гущинский A.A. и др. // ХIX Международная Черняевская конференция по химии, аналитике и технологии платиновых металлов. Новосибирск: ИНХ СО РАН, 2010. С. 105-106.

[12] Павлов Е.А. и др. // Цветные металлы-2009: Сб. докладов I Международного конгресса. Красноярск, 2009. С. 626-629. 